\title{
Utopías en la era de la supervivencia. Una interpretación del Buen Vivir Omar Felipe Giraldo
}

\author{
Editorial Itaca, México D.F., 2014, 220 págs. \\ Ricardo Andrés Lozada
}

Email: ralozadar@gmail.com

Omar Felipe Giraldo, pensador, académico e investigador colombiano, presenta un sobresaliente libro que deslumbra por su profundidad y por su fina argumentación teórico-filosófica. Es un valioso aporte que contribuye al fortalecimiento de la ecología política y del pensamiento ambiental latinoamericano.

La era de la supervivencia es para el autor un periodo de inflexión, durante el cual se puede continuar el rumbo suicida en el que estamos encauzados, o, por el contrario, virar la dirección del timonel, lo cualfinalmente determinará la supervivencia de la especie humana sobre la Tierra. Esta etapa histórica, en palabras de Giraldo,“constituye el proceso más radical de profundización y consumación de la modernidad capitalista” (p.59), hecho que ha conllevado a una crisis de la civilización, cuyos efectos pueden analizarse en muchos frentes, pero quepuede caracterizarse como una insurrección de la naturaleza a consecuencia de la emancipación que la humanidad ha emprendido para dominarla y manipularla a su antojo.

Omar Felipe argumenta que la separación cultura/naturaleza es el mayor problema ontológico de la civilización occidental y constituye la principal causa de la devastación ecológica múltiple, en donde el cambio climático y la sexta extinción masiva de la biodiversidadrepresentan dos de sus secuelas más dramáticas. La cultura occidental en su afán de aprehender la naturaleza como si se tratara de un objeto, olvida que "nuestro ser solo es posible que sea, en una relación intersubjetiva con todo lo demás, es decir, en el vínculo con otros sujetos plantas, otros sujetos animales, otro sujeto agua, e incluso, otros sujetos como el carbón o elpetróleo” (p.72).

Para explicarla sofisticación de dispositivos de poder que reproducen el orden existente, Giraldo emplea el concepto de ideología, categoría analítica que ayuda entender como la ideología tiene como fin legitimar el poder por medio de la elaboración de discursos que se auto constituyen en verdades incuestionables. El autor, siguiendo a Ricoeur, sostiene que la ideología tiene tres funciones: 1 ) La deformación o distorsión de la representación imaginaria denuestra relación con el mundo, determinada por los intereses dominantes que surgen de las interacciones desiguales entre ac- 
tores. 2) La legitimación del orden existente para disminuir los costos que representa su permanencia, estableciendo discursos de verdad que al ser aceptados, validados, interiorizados y constantemente reproducidos, se convierten en costumbres mecánicas que reproducen el poder como estrategia de dominación. 3) LaIntegración, como un cuerpo coherente de imágenes e ideas compartidas que se usan para mantener un orden establecido, a través de un discurso lingüístico que provoca que los grupos humanos se resistan al cambio por la seguridad que produce el hecho de sentir un orden determinado como propio.

La ideología es el dispositivo de poder que busca preservar el estado de cosas, mientras que la utopía intenta trastocar el sentido y la praxis de lo existente. Tanto ideología como utopía luchan por el poder, la primera designando a la segunda como una fantasía, como un sueño imposible de alcanzar, como un ideal en un futuro que no se conseguirá, en tanto la utopía intenta derrumbar el orden hegemónico y transformarlo por otro diferente. La utilidad de esa elaboración teórica está en la interpretación del Buen Vivir como una utopía que se contrapone a la ideología de la modernidad capitalista, lo cual es la pieza principal de análisis realizado a lo largo del libro.

Después de analizar las principales patologías de la utopía, Giraldo propone la noción de utopías posibilistas. Se trata de esas utopías quereconocen que no existe una sola utopía en singular, sino múltiples y diversas utopías que responden a la pluralidad, complejidad y cantidad de territorios existentes.Las utopías posibilistas están orientadas bajo el principio de la alteridad e interculturalidad y alejadas de una idea lineal del tiempo fundamentado en la esperanza interminable de que algo pasará, de que algo está por venir. Por el contrario, y es aquí donde se presenta uno de los argumentos más importantes del libro, la imaginación y construcción de utopías, deben tener como referente el aquí y el ahora, en pensamientos, acciones, valores y relaciones vivas en las cuales podamos inspirarnos para volvernos creativos.En éste sentido, las utopías deberán construir sus imaginarios creativos, partiendo de la crítica a los dispositivos de dominación de la modernidad capitalista, con el fin de anteponer nuevos discursos lingüísticos que conlleven a la destrucción de los símbolos culturales del pensamiento moderno, símbolos que tienen hoy en día a la madre tierra y a la especie humana, inmersos en lo que el autor denomina la era de la supervivencia.

Partiendo de estos elementos conceptuales, el autor hace una interpretación del Buen Vivir como una utopía posibilista, cimentada "en racionalidades, formas de interpretar el mundo y prácticas vivas de diversas comunidades rurales latinoamericanas”(p.102). El elemento principal para comprender el Buen Vivir es el concepto de la relacionalidad, noción que se contrapone al símbolo dominante que ha deformado nuestros imaginarios de la realidad y que presenta al ser humano como algo separado y no dependiente de los demás seres vivos y elementos de la naturaleza. Otro elemento discursivo de la utopía del Buen Vivir es el de la complementariedad, 
símbolo que se contrapone al de la competencia, noción básica de la modernidad que conlleva a la necesidad y obligatoriedad de eliminar o vencer al otro. "El principio de la complementariedad es, en definitiva, una racionalidad intersubjetiva, fincada en la comunidad, en donde todos somos sujetos que nos necesitamos los unos a los otros” asegura (p.109).En conclusión, la utopía del Buen Vivir se crea y recrea gracias a racionalidades existentes que escapan al pensamiento moderno y que descubren otras formas de habitar la Tierra.

El Buen Vivir es una realidad y como tal se contrapone al discurso del Vivir Mejor, éste último enmarcado en la idea de un progreso sustentado en las ideologías de la individualidad, competencia, ambición, egoísmo y desarrollo, siempre con un sentido antropocéntrico, creyendo queel humano es el único sujeto con derechos y el ser superior que domina la naturaleza para satisfacer sus propias ambiciones. Aquí el autor expone de manera clara otro concepto clave para entender la realidad de las utopías posibilistas: el reconocimiento de los Derechos de la Madre Tierra en las constituciones de Ecuador y la legislación boliviana, ejemplo contundente que muestra que las utopías son posibles, y que la idea de poner en un mismo lugar al ser humano con los demás sujetos y seres de la naturaleza, representa un hecho concreto que impugna uno de los dispositivos de dominación más representativos de la modernidad: entender la naturaleza como un objeto, como un utilitario "recurso natural".

En el libro se resaltan la comunalidad, la solidaridad, y la cooperación como los valores llamados a enfrentar y reemplazar los símbolos culturales de la modernidad. Sin embargoe interpretando el concepto de crisis civilizatoria que muy bien desarrolla el autor, el egoísmo sería el factor último que impulsaría la transformación de los símbolos culturales dominantes, ya que en la era de la supervivencia, el temor que sentimos a la muerte, al sufrimiento y a la desaparición como especie, nos conduciría a transmutar la manera como nos relacionamos con la madre tierra. Al final no queda claro si es la empatía o el temor a la auto-extinción lo que finalmente llevará al ser humano a destruir los símbolos culturales de la modernidad. Es decir ¿qué lo hará sentirse parte constitutiva de la madre tierra? y ¿qué hará que termine con la idea de creerse la especie suprema que tiene el derecho a explotar y destruir las demás formas de vida?

En conclusión, el Buen Vivir como utopía nos enseña que si el ser humano quiere cambiar el rumbo, debe comprender que dependemos de los otros seres vivos y de los elementos de la naturaleza para sobrevivir. En el fondo del asunto está la vida del ser humano y la contradicción más interesante que veo es que la madre tierra podría existir sin los seres humanos, pero los seres humanos no podríamos vivir sin los regalos de la madre tierra. Entonces ¿Por qué no llamar a esto una crisis de la vida y no una crisis civilizatoria? En conclusión, se necesita una revolución cultural que interiorice en los seres humanos el respeto por la vida, más allá de si ese respeto es necesario para nuestra supervivencia o no. Esta sería la verdadera revolución cultural. 
Creo que la tecnología y la ciencia podrían jugar un papel preponderante en ésta revolución cultural. La ciencia no es mala per se, lo que quiere decir que su desarrollo y direccionamiento dependen de los símbolos culturales y relaciones de fuerza que hay detrás de ella. En este sentido, creo que el libro deja de lado una herramienta que no debería ser ajena al Buen Vivir. Si bien el problema de fondo son los símbolos culturales de la modernidad, en el proceso de transformación, la tecnología y la ciencia podrían ser herramientas aliadas. El cambio cultural es un proceso de transformación paulatina y las campañas para fomentar la producción limpia, el reciclaje, el uso de materiales biodegradables y las tecnologías que disminuyen el uso de elementos contaminantes, así sean creadas por los dispositivos de dominación, son maneras de ir construyendo esa conciencia de cambio cultural que enseña el Buen Vivir, tal vez más aplicados a la imaginación de un Buen Vivir urbano.

En todas las culturas la creatividad hace parte de las relaciones sociales. En unas se alcanzan altos niveles de sofisticación mientras que en otras sólo tienen el objetivo de mejorar las técnicas para cazar, para protegerse de la lluvia, del sol o del mar. La creatividad en algunas ocasiones está ligada al instinto por competir y por hacer las cosas más fáciles. Así, los barcos se van mejorando, los aviones, los trenes, la ropa, las armas, las estrategias de guerra, las viviendas, la escritura, los sistemas de alcantarillado, acueducto y energía eléctrica. Esta situación siempre ha hecho parte del ser humano, su naturaleza lo impulsa a crear, a mejorar los procesos, las técnicas. Dicha creatividad podría orientarse en el diseño de tecnologías que respeten las otras formas de vida, como por ejemplo, hacer sistemas de transporte que no contaminen, o en el mejoramiento de los sistemasagroecológicos. En conclusión, la creatividad del ser humano no se puede limitar, se debe reorientar hacía los valores del Buen Vivir, sobretodo un Buen Vivir pensado para habitar de otras maneras las ciudades.

Giraldo plantea que la educación es la herramienta más poderosa para llevar a cabo una transformación como la que requiere nuestra era. Sin embargo, argumenta que para que sea efectiva deberá partir de la experiencia personal, de sentir el mundo y la naturaleza de otra manera. Pero creo que el libro no es claro en presentar cuál será el actor social o el responsable de liderar esa revolución cultural. Si bien aclara que no es posible dar recetas generales, ya que cada territorio tiene su particularidad, creo que hubiera sido interesante dar más luces que iluminen el camino a seguir. ¿Deberá ser el Estado? ¿Los movimientos sociales? ¿Las comunidades amerindias? Creo que la infraestructura institucional de los Estados Nación es necesaria para impulsar esta transformación. Sin embargo deberá ser influenciada, presionada y cooptada por movimientos sociales urbanos, campesinos e indígenas. La era de la supervivencia es ahora, y sólo una fuerza social será capaz de enfrentar, deconstruir y posicionar los nuevos símbolos que se necesitan para salvar al ser humano de sí mismo. En éste sentido si esperamos a que cada ser humano tenga una vivencia personal pienso que no habrá tiempo de salvar a la humanidad de su auto-extinción. 
Ahora ¿cuál es el paso a seguir? Creo que hay que transmitir estos importantes y esclarecedores planteamientos en lenguajes que sean comprensibles para lectores alejados de la academia. Es un reto grande, pero hay que hacerlo, de lo contrario no pasará de ser un libro de necesaria consulta en los círculos académicos. La creatividad y la imaginación no sólo se necesitan para pensar, descubrir, comprender y construir las utopías. Se necesitan también para crear estrategias, dispositivos y métodos que las hagan posibles. La educación ambiental es quizás una de las herramientas más apropiadas para esta transformación, pero es necesario ir más allá y comprender que un cambio cultural requiere de acciones concretas que deben ser propuestas desde el pensamiento y la praxis.

Los apuntes aquí presentados son una pequeña muestra de la riqueza conceptual y complejidad analítica del libro de Omar Felipe Giraldo, que sin duda alguna se convertirá en un libro de necesaria consulta en el diseño de políticas públicas y que de ser comprendido en todas sus dimensiones, permitirá repensar de manera crítica la manera como habitamos la madre tierra. 